\title{
Study of Heavy Metals SpeciationCharacteristics in Agricultural Soil Near Smelting and Mining Areas of Hezhang, China
}

\author{
Meryem Briki ${ }^{1, a}$, Hongbing $\mathrm{Ji}^{1, \mathrm{~b}}$, Huaijian Ding ${ }^{1, \mathrm{c}}$ and Cai $\mathrm{Li}^{1, \mathrm{~d}}$ \\ ${ }^{1}$ Civil and Environmental Engineering School, University of Science and Technology Beijing, \\ Beijing 100083, China

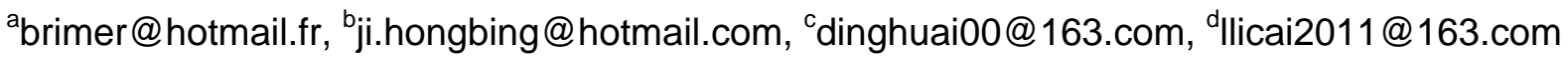

\begin{abstract}
Keywords: Smelting area, Mining area, Speciation, Heavy metals, Tucker 3, BCR
Abstract: A study of characteristics and speciation of 7 heavy metals in agricultural soil near mining smelting of Hezhang were analyzed. The heavy metal concentration were determined by using ICPOES, the chemical fraction concentrations of heavy metal extraction were used a modified BCRSEPs. Tucker 3 was used to analyze the relationships between speciation data. Our results showed that the concentration of $\mathrm{As}, \mathrm{Cd}, \mathrm{Co}, \mathrm{Cu}, \mathrm{Ni}, \mathrm{Zn}$ and $\mathrm{Cr}$ in all studied areas were higher than background of Guizhou, whereas $\mathrm{As}, \mathrm{Cu}, \mathrm{Zn}$ and $\mathrm{Cd}$ were higher in mining area; $\mathrm{Ni}$ and $\mathrm{Cr}$ in mountainous area and Co in smelting areas. Zinc was the most serious pollution element in all studied areas. The chemical speciation of heavy metals were relatively higher in residual fraction (F4) especially $\mathrm{Cu}$ and $\mathrm{Cr}$ in the studied areas. The Co element was the highest percentage in acid secondary-phase (F1+F2+F3). However some elements such as $\mathrm{Zn}$ in mining area and As, Co in both smelting and mountainous areas were relatively high in reducible fraction (F1). Tucker 3 results showed As, Cd, Cu, Zn, mainly from mining and smelting activities, mining areas (M1, M2, M15) was particularly evident, mainly in residual fraction. Cu was mainly due to the impact of mining and smelting (Model B1), while a small part of Cu exhibited similar source to Co, Cr, Ni (Model B2).
\end{abstract}

\section{Introduction}

Heavy metal pollution in different components of environment has become a global environmental concern; soil is one of most essential components of the environment and it is the most direct storage of elements [1]. In recent decades metals mining and smelting have been important source of contamination in the environment because of waste and transportation of human activities [2]. Hence, it is necessary to identify and quantify the level of heavy metals to understand the transportation and deposition in soil. An assessment of total amount heavy metal pollution may be useful as global index of contamination, but it give limited information of their bioavailability, mobility and reactivity in soils [3]. According to Tessier et al. [4], the evaluations of the individual fractions of the metals facilitate the understanding of the actual and potential environmental effects. The Sequential extraction procedures (SEPs) are applied to evaluate the heavy metal mobility in soil [5]. BCR-SEPs are designed to separate heavy metal into four operationally distinct fractions: 1 ) acid soluble/exchangeable, 2) reducible, 3) oxidizable, and 4) residual fractions [6]. Meanwhile the relationships between sample, heavy metal and fractions data [Sample $\times$ metal $\times$ Fraction] in soil is studied by the Tucker 3 model analysis $[7,8]$.

Based on the issues described above, this research was conducted in Hezhang (China). Hezhang is County of Bijie City in Guizhou province, located in southwest of China. Hezhang is previously known as an artisan Zn smelting using indigenous methods practiced in Guizhou for hundreds of years, from at least the seventeenth century until 2004, when the practice stopped. Since the $17^{\text {th }}$ century, artisanal zinc smelting using indigenous methods had been extensively applied in Hezhang County. The zinc smelting activities were ceased due to the concern of environmental pollution [9]. The objectives of this study were: (1) to analyze the total contents of selected metals As, Cd, Co, Cu, $\mathrm{Ni}, \mathrm{Zn}$ and $\mathrm{Cr}$; (2) to interpret the mobility, dynamics and risk assessment of studied metals by using modified BCR- SEPs; (3) to investigate the relationships of soil heavy metals fraction in agricultural soil of mining, smelting and mountainous areas of Hezhang. The result of this study may provide information about risk, mobility of heavy metal in the studied areas. 


\section{Materials and Methods}

Sampling. In this study, 19 samples were collected from the smelting area, mining area and mountain. Specific sampling information: 1) 13 samples in smelting area (SM): 2 in Shehucun (ZB), 3 in Shijiapo (ZBL), 4 in Haimeicun (LA) and 4 in Longjiayuan (ZZ); 2) 5 soil samples in mining area (MM): Shangermachong; 3) 1 sample in mountainous area (HZS). The sample sites see the location sites in Briki et al. [10]. The soil samples were collected in agricultural field from 0-15 $\mathrm{cm}$. Every sample was placed in a polyethylene bag, which was preserved and transported to the laboratory. Every sample was dried at $45^{\circ} \mathrm{C}$ in an oven until constant weight, then ground using an agate ball mill. The sample was then passed through a 200-mesh sieve to determine the concentration of heavy metals.

Chemical analysis. Total contents and fraction concentrations of $\mathrm{As}, \mathrm{Cd}, \mathrm{Co}, \mathrm{Cu}, \mathrm{Ni}, \mathrm{Zn}$ and $\mathrm{Cr}$ in the soil samples were measured with inductively coupled plasma-optical emission spectrometer (ICP-OES, Varian 700-ES (Varian, Inc., Walnut Creek, CA). The processing of the analysis, blank samples, standard, and duplicate samples were realized by following Huang et al. [8].

\section{Results and Discussions}

Total content of heavy metals. The concentrations of $\mathrm{As}, \mathrm{Cd}, \mathrm{Co}, \mathrm{Cu}, \mathrm{Ni}, \mathrm{Zn}$ and $\mathrm{Cr}$ are presented in Table 1. The metal concentration in mining, smelting and mountainous areas exceeded the background levels in Guizhou and only Cd in smelting and mountainous areas were less than the background concentrations. Furthermore the concentration of $\mathrm{As}, \mathrm{Cu}, \mathrm{Zn}$ and $\mathrm{Cd}$ in agricultural soil from mining area were higher than smelting and mountainous areas; the concentration of Co was higher in smelting areas than mountainous and mining areas. However $\mathrm{Ni}$ and $\mathrm{Cr}$ concentration were relatively higher in HZS, this might be due to the transportation of metals in air or during entrained soil particles after being emitted from mining and smelting activities [11].

From the range of metal contents in mining and smelting areas, the difference between the maximum and minimum values was relatively higher. Zinc was the highest contaminant in mining, smelting and mountainous areas. In mining area $\mathrm{Zn}$ was higher because of the closeness between sampling agricultural soil and working area. The transportation of metal was one of the most important way of dissemination of metals into soil. And Zn was high in smelting areas due to the earlier zinc smelter [10]. Overall anthropogenic activities were the main cause of the higher concentration in both mining and smelting areas.

Table 1. Total content of heavy metal concentrations of all samples

\begin{tabular}{|c|c|c|c|c|c|c|c|c|c|}
\hline \multirow{2}{*}{$\begin{array}{l}\text { Elements } \\
{\left[\mathrm{mg} \mathrm{kg}^{-1}\right]}\end{array}$} & \multicolumn{2}{|c|}{ Maximum } & \multicolumn{2}{|c|}{ Minimum } & \multicolumn{2}{|c|}{ SD } & \multicolumn{3}{|c|}{ Mean } \\
\hline & $\begin{array}{l}\mathrm{MM} \\
\mathrm{n}=5\end{array}$ & $\begin{array}{c}\mathrm{SM} \\
\mathrm{n}=13\end{array}$ & $\begin{array}{l}\mathrm{MM} \\
\mathrm{n}=5\end{array}$ & $\begin{array}{c}\text { SM } \\
n=13\end{array}$ & $\begin{array}{l}\mathrm{MM} \\
\mathrm{n}=5\end{array}$ & SM & $\begin{array}{l}\mathrm{MM} \\
\mathrm{n}=5\end{array}$ & $\begin{array}{c}\mathrm{SM} \\
\mathrm{n}=13\end{array}$ & $\begin{array}{c}\text { HZS } \\
n=1\end{array}$ \\
\hline As & 266.00 & 30.05 & 60.50 & 16.60 & 90.02 & 4.95 & 154.18 & 22.82 & 20.80 \\
\hline Cd & 121.14 & 15.89 & 8.56 & 1.86 & 51.19 & 4.27 & 69.50 & 7.68 & 16.66 \\
\hline Co & 37.60 & 54.50 & 15.90 & 22.70 & 8.12 & 10.06 & 24.92 & 40.21 & 38.40 \\
\hline $\mathrm{Cu}$ & 644.66 & 327.32 & 62.75 & 53.38 & 261.11 & 103.81 & 318.13 & 161.39 & 98.10 \\
\hline $\mathbf{N i}$ & 94.68 & 166.81 & 72.71 & 43.46 & 10.24 & 40.12 & 83.47 & 107.24 & 120.68 \\
\hline Zn & 31108.12 & 962.09 & 2259.65 & 150.73 & 11952.58 & 286.53 & 13940.84 & 408.27 & 388.72 \\
\hline $\mathrm{Cr}$ & 181.10 & 427.77 & 108.02 & 79.81 & 26.70 & 112.61 & 147.51 & 210.99 & 306.68 \\
\hline
\end{tabular}

Speciation of heavy metals. Heavy metal speciation of the extracted elements percentage of As, Cd, $\mathrm{Co}, \mathrm{Cu}, \mathrm{Ni}, \mathrm{Zn}$ and $\mathrm{Cr}$ are showed in Fig 1. As can be seen from Fig 1, the common characteristics of these elements had the highest proportion in residual fraction (F4).

Acid soluble fraction (F1) was considered to be most biologically available form but also most easy to transport and transformation of metals. In mining area, $\mathrm{Zn}$ and $\mathrm{Cd}$ were the highest values with proportion of $21.04 \%$ and $15.76 \%$ respectively. In smelting areas, As, Co and Cd were the highest elements with $16.73 \%, 16.68 \%$ and $10.36 \%$ respectively. In mountainous area, the percentage of As, Co and Cd were $21.81 \%, 16.74 \%$ and $8.43 \%$, respectively. In acid soluble fraction Zn was the highest percentage in mining area and As, Co and Cd were the highest percentage in smelting and mountainous areas, meaning that those elements were mobile and bio-available in 
those areas. However the lowest F1 percentage of selected metals in mining, smelting and mountainous areas was $\mathrm{Cr}$, which might be due to its inability of mobility. $\mathrm{Cr}^{3+}$ cannot precipitate or co-precipitate with carbonate complexation, and the similar result was found in Huang et al. [8].

In reducible fraction (F2), Co and $\mathrm{Zn}$ in mining were higher with $33.38 \%$ and $15.14 \%$ respectively. In smelting areas, $\mathrm{Co}, \mathrm{Cd}$ and As elements in reducible fraction (F2) were higher, and the proportion of the total amount were $26.97 \%, 19.38 \%$ and $14.67 \%$ respectively. In mountainous area Co, Cd and Zn proportion total amount were 29.42\%, 12.35\%, 8.14\% respectively. Arsenic metal did not exist in F2. Co in reducible fraction was obviously high in the study areas, which may be caused by organic complex and water soluble oxidation state.

In oxidizable fraction (F3), according to Huang et al. [8], F3 was related with sulfide mineral or organic material. $\mathrm{Co}, \mathrm{Ni}$ and $\mathrm{Cr}$ in mining area had higher percentage $17.28 \%, 16.56 \%$ and $14.34 \%$ respectively. In smelting areas $\mathrm{As}$, Co and $\mathrm{Ni}$ had higher percentage with the proportion of $21.82 \%$, $16.40 \%$ and $14.60 \%$ respectively. And in mountainous area higher percentage was observed in Co, $\mathrm{Cu}$ and Ni with proportion values of $15.36 \%, 9.14 \%$ and $8.77 \%$ respectively. The Cd metal did not exist in F3. In residual fraction (F4), the speciation data of $\mathrm{As}, \mathrm{Cu}, \mathrm{Cr}, \mathrm{Cd}, \mathrm{Ni}, \mathrm{Zn}$, Co were dominant in mining area; $\mathrm{As}, \mathrm{Cu}, \mathrm{Cr}, \mathrm{Zn}, \mathrm{Ni}, \mathrm{Cd}$, and Co dominant in smelting areas and $\mathrm{Cr}, \mathrm{Cu}, \mathrm{Ni}$, Zn, Cd, As and Co dominant in mountainous area .
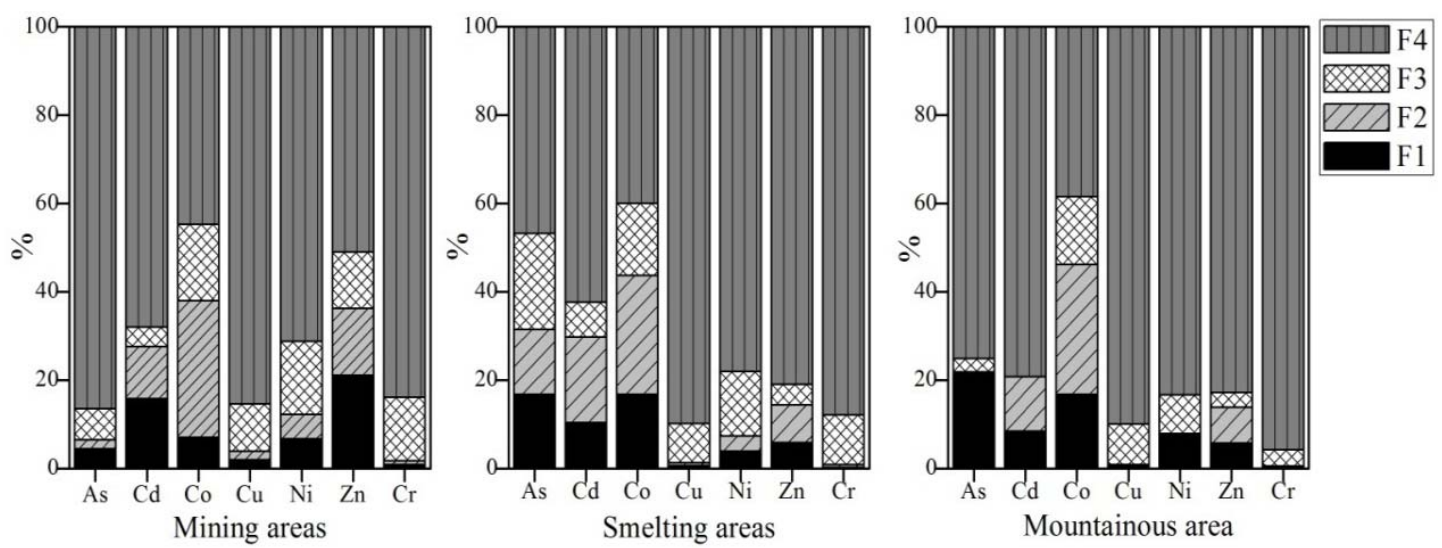

Fig 1. Percentage of heavy metal extracted from the BCR steps in mining, smelting and mountainous areas

Tucker 3. By using Tucker 3 models, the information of BCR database with tri-dimensional $(19 \times 7$ $\times 4)$ was analyzed, knowing that $\left(n_{\text {Sample }} \times n_{\text {Metal }} \times n_{\text {Fraction }}\right)$. The results of theses analysis give information regarding the characterization and distribution of the fractionation of metals. To obtain optimal model, a percentage of explained variance for all models using the smallest amount latent factors in each mode from [1 11 1] to [19 7 4]. As shown in Fig 2, [3 2 2] presented 78.49\% of total variance. A further increase in terms better explained the variance, but made the models difficult to interpret. Thus, [l $\left.\begin{array}{ll}3 & 2\end{array}\right]$ w was selected as the optimal model for this research.

Fig 3 showed a summary of the component of the tucker 3 [3 2 2 2 ] model; which was composed of three (3) loadings of the three (3) matrixes: (A) was representing samples, (B) was representing metals and (C) was representing fraction. There were three factors in A model and two factors for the metal and BCR fraction (B and C models). To completely separate the information of Tucker 3

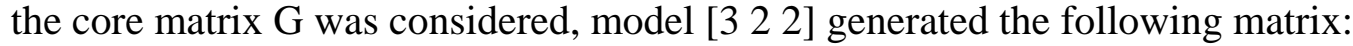

$\begin{array}{llllll}\text { g111 } & \text { g211 } & \text { g311 } & \text { g121 } & \text { g221 } & \text { g321 } \\ \text {-15.4435 } & 0.0203 & -0.2956 & 0.0324 & -10.7773 & -1.2660 \\ \text { g112 } & \text { g212 } & \text { g312 } & \text { g122 } & \text { g222 } & \text { g322 } \\ 0.6177 & 5.6521 & -2.5095 & 4.0038 & -0.7062 & -0.7426\end{array}$

Three components in A model represented different values. The model A1 was on the component 


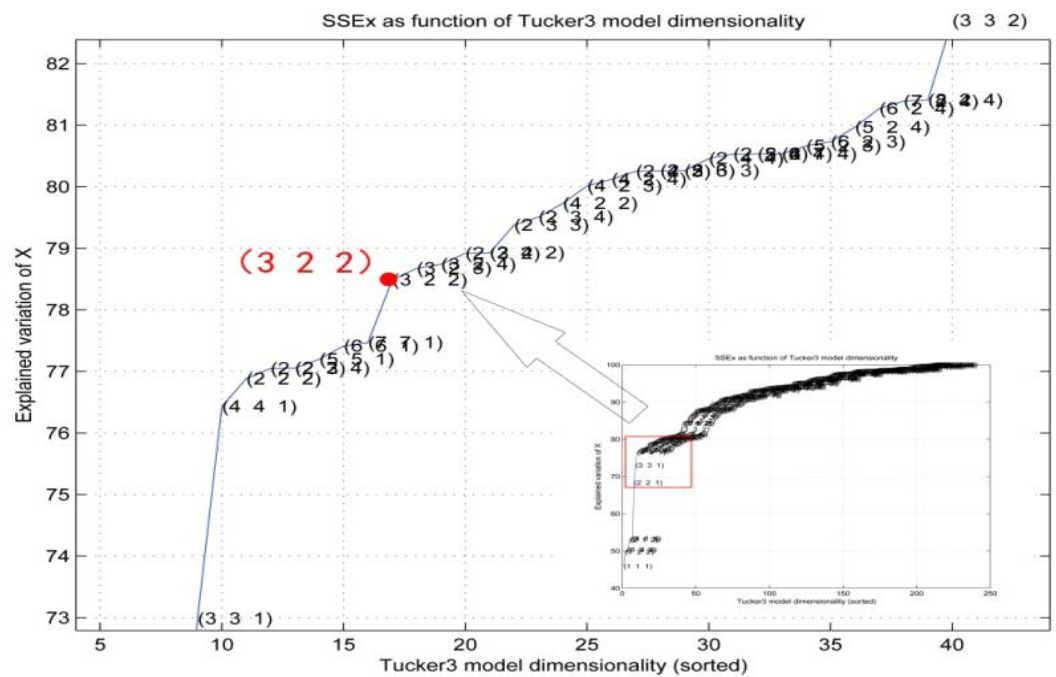

Fig 2. Explained percentage of variance versus model dimensionally as determined by Tucker 3 modeling of the BCR fractions in all studied samples of Hezhang
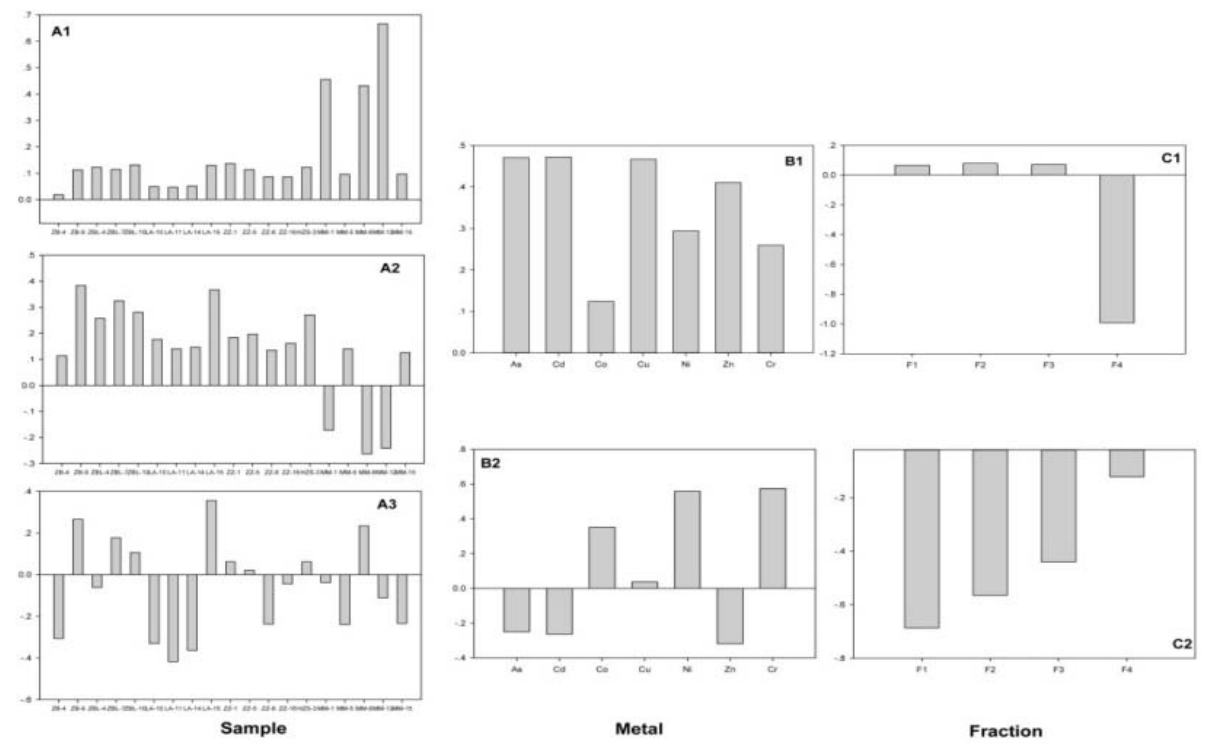

Fig 3. Loadings of the Tucker 3 [ $\left.\begin{array}{lll}3 & 2 & 2\end{array}\right]$ model of the BCR fractions results. (a) Factor 1 (1) samples;

(2) metals; and (3) fractions. (b) Factor 2 (1) samples; (2) metals; and (3) fractions.

who had positive loadings in all samples, with MM1, MM8 and MM12 having the highest values (mining area). The model A2 contained both positive and negative loadings, but most of the samples had positive loadings, negative loadings were in MM1, MM8 and MM 12 and the rest samples were positive loadings. It was remarkably observed that MM1, MM8 and MM 12 in A1 were inversed in A2. However the model A3 contained negative loadings more than positive loadings. As seen in Fig 3, mining areas including MM1, MM12 and MM15 were the most serious pollution points, and these pollution characteristic were significantly different from (model A2) smelting and mountainous areas, and the distribution of A3 was completely different comparing to A1 and A2. However mountainous area (HZS 3) was positive loadings in all models (A1-A2 and A3).

In B model, $\mathrm{Co}, \mathrm{Ni}$ and $\mathrm{Cr}$ had similar characteristic, less value in $\mathrm{B} 1$, and all positive values in $\mathrm{B} 2$, it seemed that they were more similar, maybe the same source. And in B2, Cu also had positive value. Thus we can infer that $\mathrm{Cu}$ may be a mixed source, with most of $\mathrm{Cu}$ similar to $\mathrm{As}$, $\mathrm{Cd}$ and $\mathrm{Zn}$, and the rest similar to $\mathrm{Co}, \mathrm{Ni}$ and $\mathrm{Cr}$. Combined with the pollution characteristics found in the study of Briki et al., [10] (e.g., Zn, As and Cd were a source of anthropogenic pollution Pb-Zn mine ore for mining area and from zinc smelting ceased in 2004 for smelting areas), Co, $\mathrm{Ni}$ and $\mathrm{Cr}$ belonged to nature process. For $\mathrm{C}$ model (fractions), in the first factor (C1), only fraction 4 was negative, 
which played a dominant role due to the higher absolute loading value. Whereas the second factor (C2) contained negative loadings for all fractions.

\section{Conclusions}

The metal concentrations in mining and smelting areas exceeded the background levels of Guizhou. And the heavy metals levels were higher in mining area than smelting areas. Zinc was the most polluted heavy metal in mining areas. The percentage of the bioavailable metals in mining and smelting areas were different, with mining area following the order of $\mathrm{Zn}>\mathrm{Cd}>\mathrm{Co}>\mathrm{Ni}>\mathrm{As}>\mathrm{Cu}>$ $\mathrm{Cr}$, smelting areas $\mathrm{Co}>\mathrm{As}>\mathrm{Cd}>\mathrm{Zn}>\mathrm{Ni}>\mathrm{Cu}>\mathrm{Cr}$ and mountainous area $\mathrm{As}>\mathrm{Co}>\mathrm{Cd}>\mathrm{Ni}>\mathrm{Zn}>$ $\mathrm{Cu}>\mathrm{Cr}$. The Co element was the highest percentage in acid soluble reducible fraction and oxidizable $(\mathrm{F} 1+\mathrm{F} 2+\mathrm{F} 3)$ However, some elements such $\mathrm{Zn}$ in mining area and As, Co in both smelting and mountainous areas were relatively high in reducible fraction. $\mathrm{Cu}$ was present in residual fraction in all studied areas. As, Cd, Cu, Zn, mainly from mining and smelting activities, mining areas (M1, M2, M15) was particularly evident, mainly in residual fraction. $\mathrm{Cu}$ was mainly derived from the mining and smelting activities (Model B1), while a small part of $\mathrm{Cu}$ exhibited similar source to $\mathrm{Co}$, $\mathrm{Cr}$, Ni (Model B2).

\section{Acknowledgements}

This work was jointly supported from the National Natural Science Foundation of China (Nos. 41173113, 41473122) and the Hundred Talents Programs of Chinese Academy of Science.

\section{Literature References}

[1] J. Sapunar-Postruznik, D. Bazulic, H. Kubala: Sci. Total. Environ. Vol. 191(1996), P. 119.

[2] I. Thornton: Appl. Geochem. Vol. 11 (1996), P. 355.

[3] X. S. Luo, D. M. Zhou, X. H. Liu, et al: J. Hazard. Mater. Vol. 131 (2006), P.19.

[4] A. Tessier, P. G. C. Campbell, M. Bisson: Anal. Chem . Vol. 51(1979), P. 844.

[5] A. Guevara-Riba, A. Sahuquillo, R. Rubio, et al: Sci. Total. Environ. Vol. 321 (2004), P.241.

[6] C. M Davidson, G. J Urquhart, F. Ajmone-Marsan, et al: Anal. Chim. Acta. Vol. 565 (2006), P.63.

[7] H. J Ding, H. B Ji: Environ. Earth. Sci. Vol. 61(2010), P. 641.

[8] X. Huang, Y. Zhu, H. Ji: Environ. Monit. Assess. Vol. 185(2013), P. 8525.

[9] X. Bi, X. Feng, Y. Y. Yang, et al: Environ. Int. Vol. 32(2006), P. 883.

[10] M. Briki, H. B. Ji, C. Li, H. J. Ding, Y. Gao: Environ. Monit. Assess. Vol. 187 (2015), P.1.

[11] M. Rashad, E.A. Shalaby: American-Eurasian J. Agric. \& Environ. Sci. Vol. 2 (2007), 204. 